\title{
Gillian Greenwood: 'Every time you get knocked down you have to stand up again and keep trying'
}

Please send any ideas for feature articles for consideration to:

Ruth Doherty,

Managing Editor,

British Dental Journal

The Macmillan Building,

4-6 Crinan Street,

London,

N1 9XW

Email: r.doherty@nature.com

Ahead of her talk at the 2013 British Dental Conference Et Exhibition, the British Dental Journal caught up with Gill Greenwood, to find out about the nitty-gritty of special care dentistry.

\section{What or who inspired you to become a dentist?}

One day, when I was about 13, I was off school ill watching our old black and white telly when Lord Rix and his daughter Shelley appeared on a programme talking about dentistry for disabled people. Then the next programme was about dentistry in the Royal Navy. I thought: 'That's interesting, what about dentistry as a career?' I really hadn't considered it at all until then.

My own dentist was also a big factor. Believe it or not I am seriously dentally phobic! However, my dentist, Glenn Rochester, who was my dentist for around thirty years, was so gentle and kind that I even allowed him to take my wisdom teeth out under local anaesthetic. I thought: 'If he can do that for me, can I do it for someone else?' I also knew I wanted to do something with my hands so it all came together and I realised I wanted to be a dentist.

I remember telling the school's careers officer and they laughed me out of the room advising me to be a hairdresser. A boy in my class was told 'yes of course' and received lots of support but they felt dentistry was inappropriate for me, as a woman. That was 1978. In 1980 at my Royal Dental Hospital interview, the first question they asked was: ‘Aren’t you just going to go and get married and have children?'! Thank god for my mum. She was high up in Barclay's Bank in the 1950s, which was unusual for a woman then. She used to say: 'Just go for it!' So I did. I had to retake A levels and battle very hard, but I got there. I am very proud of that.

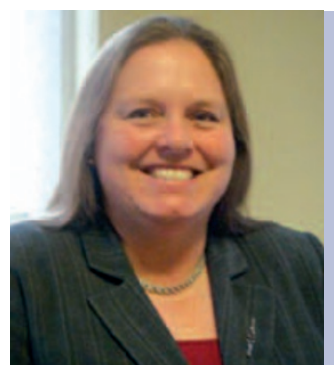

Gillian Greenwood (née Marshall) qualified at the London Hospital in 1985 and went on to work there as a house officer in restorative dentistry. This was followed by resident, SHO, and registrar posts in OMFS. Gill also spent two years as a full time GDP. Since then she has followed her dual and converging interests of special care dentistry and oral surgery and is a registered specialist in both areas. In 2004 she joined the East Yorkshire and Hull salaried dental services and was appointed as consultant in specia care dentistry at City Health Care Partnership Hull in 2010. Gill is also the Training Programme Director of Special Care Dentistry for the Yorkshire and Humber Postgraduate Deanery and chair of BDA/CDS GMC.

Why did you choose to specialise in special care dentistry?

My mum had multiple sclerosis so that must have influenced my choice of special care. Perhaps also underpinning this path was an underlying need to be needed.

In fact, when I first started as an undergraduate I thought I might want to do crown and bridge work because I really enjoyed that from a technical point of view. However, I found I particularly loved treatment planning and whole patient care. Mentors like Terry English, John M. Richards, John Besford, Brian Littler and Hugh Walters all led me down this path through their support and example. Their approach to patient care really influenced me.

After I qualified I realised that, though I could do extractions, I couldn't do any simple surgeries and so I diverted off into max fax. I went down that route to registrar level and did lots of reasonably big surgeries. Then came a turning-point. I had to decide whether I would keep going with max fax and possibly have to give up the chance of having a family.

A special care job came up 10 miles down the road. At that time mum's MS was really bad and I knew I didn't want to do the on call required by max fax as I needed to be around for her. So that was it. I thought I've come back full circle to where I started out with Lord Rix's inspiration. A couple of years ago after I was entered on the Specialist Registrar I actually wrote to Lord Rix to thank him for his inspiration. He replied with a hand-written letter and was very gracious.

\section{What is your favourite part of the working week?}

I'm really lucky as I enjoy an awful lot of my work. I love patient care but I don't enjoy the politics and fighting the targets. I also really enjoy teaching my two speciality registrars (StRs) and their enthusiasm is incredible.

I love meeting new patients, though this can be a bit of a double-edged sword. You have no idea whether or not you will be able to meet their demands. It can be a real challenge but when you find solutions to help it's fantastic.

There was a lady I treated recently who had been in severe oral pain for two years. She is bariatric and has lots of complex medical needs. When I first saw 
her I thought she had very little capacity, she was constantly going off into absences, couldn't communicate and her husband had to be her voice. She didn't have a smile as she was missing front teeth. She wouldn't let anyone touch her mouth and because of medical problems she couldn't ever have a general anaesthetic (GA). So after much consultation and deliberation, we decided to take out the worst teeth with IV sedation (with an anaesthetic consultant) and we also made an immediate denture to give her a smile. I saw her two weeks later and didn't recognise her. She bounced into the clinic and had a full blown conversation with me. She told me that she had been unable to speak as she'd been in such appalling pain for two years. She was so happy to have been given a smile back, particularly in time for a Christmas photo with her grandchildren. Making that difference for her and her family was incredible.

\section{If you were not a dentist, what would you do?}

Probably something horsey. My mum always wanted to ride horses, so when she got married she moved to Hertfordshire and learned to ride. She decided that I should also have a pony so I've ridden since I was two and a half. I got the bug and I love it.

When my mother bought our first Shetland pony she asked the local riding school for advice on what she should feed him and they recommended nuts. So our whole family spent the entirety of Christmas shelling Brazil nuts, peanuts and walnuts for the new pony who happily ate them. Of course what they were advising was 'horse nuts' but we didn't realise this until after the 'Christmas nut shelling'!

I specialise in riding side saddle. Three years on the trot I was National Side Saddle Champion for Performance before having children! I once jumped a $5 \mathrm{ft}$ fence on side saddle - someone dared me! At our wedding, my husband and I rode from the ceremony (with me on side saddle) in our wedding outfits and that was a real dream come true. So if I wasn't a dentist I would probably be teaching people to ride.

\section{As a consultant in special care dentistry, who do you treat?}

The following definition of special care dentistry was published in 2003 by the Joint Advisory Committee of Special Care Dentistry: 'Provision of oral care for people with physical, sensory, intellectual, mental, medicinal, emotional or social needs or more often a combination of these.' Statistically 'one in four adults will have disability of some form touching their lives' so special care dentistry covers a huge range of patients.

For example, on the medical side we see many oncology patients. We also treat renal dialysis, renal transplant and severely compromised cardiac patients. Many patients are on thirty medications a day! We also treat people with physical problems such as MS (like mum), Huntingdon's and Parkinson's. There are patients with many different mental health problems; those with severe learning disorders and dementia. If you have a patient with dementia you must bear in mind their fluctuating capacity - some days they will be able to communicate and some days they won't. You just don't know what's going to happen.

\section{What is involved in delivering special care dentistry?}

It is whole patient care, whole mouth care and whole team care. So the treatment planning, assessment and fact finding can take a lot of time but if you don't get that right you can forget everything else. A lot of it is about getting to know your patient. Another side is the multi-disciplinary networking you need to do. Many patients are with multiple consultants so you need to work with them closely to deliver appropriate and timely care.

If patients haven’t got capacity best interest meetings are required. That is hours of work and you may be still getting paid through UDAs. Many of our patients also need GA or IV sedation. Some of our patients take time to transfer to a chair and someone with lots of involuntary movements due to neurological problems can take a lot of time to treat or may need the use of a hoist.

I had one patient with severe cerebral palsy who spoke incredibly slowly with a lightwriter so I always booked him in for an hour's check-up which I used to get in real trouble for as check-ups were supposed to be ten minutes! But it took him ten minutes to get into the surgery and he really wanted to speak for himself which was a slow process. When I got to know him it turned out that he was a consultant in computers. His mother told me that I was the only medical professional who actually allowed him to have his own voice. That was 20 years ago and it was acceptable for many places to allow this to happen then.

\section{What improvements do you feel should be made to the provision of care for those with special needs in the UK?}

We really need appropriate funding and appropriate access for our patients. For example, many areas have a lack of availability of GA and sedation services. In some areas, especially rural areas patients may need to travel 60-80 miles for sedation, GA or for special care dental services. This may mean they are with a different service so you can't deliver the continuity of care the patient needs. We need more equipment, such as bariatric chairs, wheelchair recliners and domiciliary equipment. It took me eight years to get a wheelchair recliner. The difference that makes to the patient and to us is incredible.

We also need consistency in the services we provide across the country. It really does depend where in the country you are as to how your care is provided. For example, in London there are a number of centres of excellence and secondary care services whereas in rural areas, secondary care services in hospital are again up to 80 miles away. For some of those patients travelling those distances isn't an option - they physically can't do it, even in an ambulance.

Ideally we need more consultant-led centres of excellence in addition to reasonable local access to appropriate services. More numbers are needed at the ground force of dental/senior dental officers, as well as in StR training programmes. Currently we only have about 30 consultants and around 300 specialists but many are nearing retirement.

Providing special care dental services is not cheap. Generally our patients don't come in for just 15 minutes. Most of our patients either don't have the money to see a private dentist or their medical needs require specialist equipment so they don't have options. We need 
commissioners and managers to truly understand their needs.

I also believe the system for oncology patients in particular needs to change. If oncology patients are referred to a special care dentistry consultant in primary care they have to pay. It's often at a time when they are not working and have limited funds. On top of all their oncology decisions they have to think are my teeth important, will I have to/or be able to pay? Perhaps it would be sensible for their dental care to be free for five years after treatment. Not for life, just at the time when they need it the most.

We must think about the long-term cost of our decisions. For example, when we are unable to look in our patients mouths without sedation, perhaps because of severe learning disability, we do a yearly sedation, an 'MOT' with an exam and $\mathrm{X}$-rays etc, to make sure everything is okay. That is costly but what could be more costly is admitting that person as an emergency with a potentially life-threatening facial swelling. This is far more distressing for the patient.

I understand that there is a financial crisis in the UK and there is only one keg of money. But, it could be any of us at any time who need this care. Lord Rix often speaks about the importance of equality of outcomes of care. Sometimes patients do need to be treated differently to have the same outcome of care.

\section{What are the main differences in providing care for vulnerable adults versus vulnerable children?}

It is quite difficult to talk about this topic as it might seem I am criticising my paediatric colleagues and I don't mean to. Providing care for vulnerable adults can mean care for life though some of our patients come to us for a period of time and then go back to their GDP - we have quite a mix. Unfortunately the present contracts don't support that terribly well.

As a consultant within primary care my patients have to pay unless exempt. The child patients of my paediatric colleagues don't have to pay so this is a big difference. A lot of our patients are with us for life and their medical needs and medication become more and more complex. If they are beginning to have short-term memory loss this becomes more profound as time goes on. Our patients become less mobile so it becomes more difficult for them to get to the surgery and even to transfer to the chair. Bariatric patients need special chairs. As patients get older and frailer they are more dependent on their carers to bring them but their carers don't always want to come or they forget.

These problems are not exclusive to adults but often become more profound for adult patients relative to children. It seems that the width and depth of care that is needed in adult special care is underestimated. Naturally, we are often compared to paediatrics.

For a patient with significant dementia, in a care home, it can take many hours to find out whether they have to pay for dental care and if they do, who pays. As I said before, if capacity to make decisions regarding dental care is lacking or fluctuating, then a best interest meeting needs to be arranged with all concerned parties (sometimes with an independent mental capacity advocate). It is the duty of the dentist/decision maker to arrange and lead this meeting.

\section{How can dentists ensure that the care they provide is patient-led?}

This quote attributed to Mahatma Gandhi really addresses this question:

'A patient is the most important visitor on our premises. He is not dependent on us. We are dependent on him. He is not an interruption to our work. He is the purpose of it.'

Dentists have got to be their patients' voice and so they need to be incredibly strong. When the UDA system first came out I was asked to go and lecture on 'special care dentistry and the new contract' at the London where I trained. We were supposed to get about 30 UDAs a day. The best I could manage was two. At that point I realised that it was totally unachievable and I wasn't going to beat myself up to try and do it.

There are lots of groups - BDA, CDS - who I know speak and consult with the DH and it will be interesting to see the change with commissioning. Every time you get knocked down you have to stand up again and keep trying and trying. Often these patients don't have a voice or options.

\section{It is said that once a special care patient has put their trust in you it is possible to provide almost any treatment - has this been your experience?}

You do need that trust and continuity of care. I have many phobic patients who wouldn't even come into the surgery and now let me do simple fillings and impressions, but that has taken several years in some cases. The continuity of the team as a whole is important too - the dental nurse, the receptionist, the secretary (if you are lucky enough to have one), the dental laboratory team, the hygienist/therapist etc.

Though trust is essential, there will always be patients who need sedation, for example those with severe learning impairment, Parkinson's or dementia. We also do use sedation for our oncology patients, particularly if they are coming in before further treatment, for example, to have teeth out before starting treatment with bisphosphonates. It can be a lot to get done in a short amount of time and they have already been through so much that their coping capabilities have often been used up. They are very grateful if we can offer them sedation as an option. So, though it's reasonably true that trust helps, we do still need the option of sedation/general anaesthesia.

\section{Why do you think society in general is wary and often fearful of people with special needs?}

Perhaps we lack understanding or have a fear of our own fragility. Also, in this society we can be impatient, always expecting instant reward, but people with special needs can take a lot of time.

\section{Did the Paralympics help?}

It was truly amazing. Since watching people at the Paralympics there are two words that aren't allowed in my own house now 'can't' and 'impossible'. Whether their achievements really get into our consciousness or whether it's a facade I don’t know. Time will tell.

Gill Greenwood will present a talk entitled 'Tips on radiology for those challenging moments' on Thursday 25 April at the 2013 British Dental Conference \& Exhibition at ExCeL London. Register online: www.bda.org/conference. 